\title{
Bibliothèques et identité visuelle
}

\section{Christophe Didier}

\section{(2) OpenEdition}

Journals

Édition électronique

URL : https://journals.openedition.org/rbnu/3083

DOI : $10.4000 /$ rbnu.3083

ISSN : 2679-6104

\section{Éditeur}

Bibliothèque nationale et universitaire de Strasbourg

\section{Édition imprimée}

Date de publication : 1 mai 2010

Pagination : 6-7

ISSN : 2109-2761

\section{Référence électronique}

Christophe Didier, «Bibliothèques et identité visuelle », La Revue de la BNU [En ligne], 1 | 2010, mis en ligne le 01 janvier 2020, consulté le 12 juin 2021. URL : http://journals.openedition.org/rbnu/3083 ; DOl : https://doi.org/10.4000/rbnu.3083

\section{(c) (i) (3)(2)}

La Revue de la BNU est mise à disposition selon les termes de la Licence Creative Commons Attribution - Pas d'Utilisation Commerciale - Partage dans les Mêmes Conditions 4.0 International. 


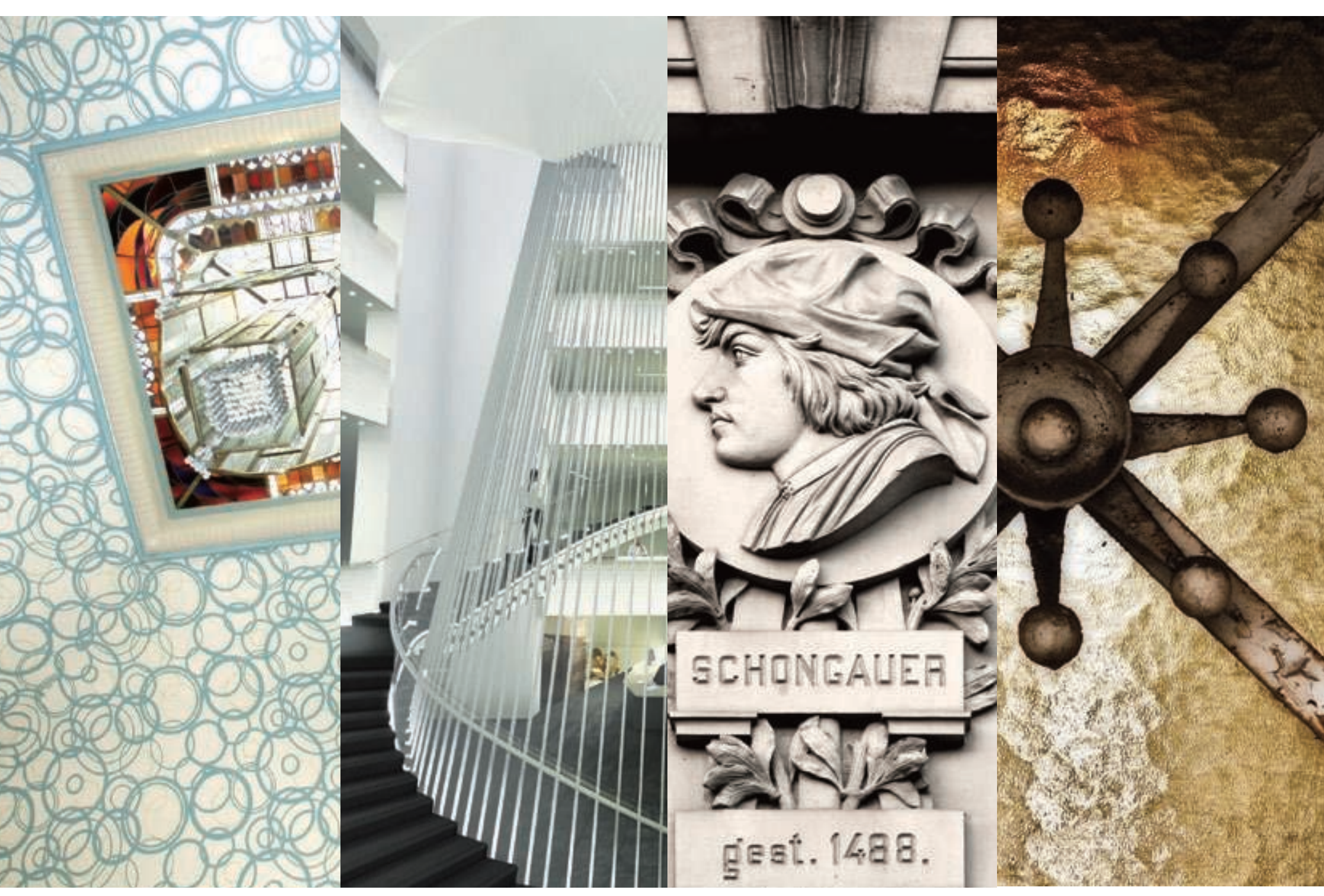




\section{LE DOSSIER \\ Bibliothèques et identité visuelle}

Les quatre livres ouverts de la Bibliothèque nationale de France, les " jardins suspendus " de l'Université Humboldt à Berlin, la transparence de la médiathèque de Sendai au Japon, les murs de hiéroglyphes de la nouvelle bibliothèque d'Alexandrie : depuis une vingtaine d'années, les bibliothèques inspirent leurs concepteurs qui leur donnent des bâtiments dont l'image est forte et cherche à délivrer un message au-delà des intérieurs jusqu'ici plutôt clos et confidentiels des salles de lecture. En ce sens, la fin $\mathrm{du} \mathrm{XX}^{\mathrm{e}}$ siècle a marqué un tournant en plaçant au cœur de la cité (et en l'affirmant avec force) des institutions jusque-là plutôt associées à l'érudition - et donc plus discrètes en termes d'image, comme il sied au silence et à la solitude du travail intellectuel. Pendant longtemps, les bibliothèques n'ont guère eu d'identité visuelle, à quelques exceptions près (parfois notoires, il est vrai, comme dans le cas des monastères allemands ou autrichiens). Mais dans la plupart des cas, hébergées dans des bâtiments au départ affectés à d'autres buts (c'est particulièrement vrai pour la France du XIX ${ }^{e}$ siècle), elles ont dû davantage obéir à des logiques d'adaptation, guère propices au développement d'identités visuelles propres. Ce n'est qu'au cours du $\mathrm{XX}^{\mathrm{e}}$ siècle que diverses nécessités (des destructions nécessitant une reconstruction, l'afflux d'un public plus nombreux, le développement de politiques de la lecture...) ont amené leurs responsables à prendre conscience de la nécessité de s'affirmer aussi symboliquement, et donc de rendre les nouveaux bâtiments aussi " parlants " que possibles, de les doter d'une identité visuelle - on dirait aujourd'hui d'une image.

On trouvera dans ce dossier six exemples, couvrant un très large $\mathrm{XX}^{\mathrm{e}}$ siècle (de 1895 à 2010), de tentatives de faire parler les bâtiments par une décoration, intégrée ou non aux projets architecturaux, mais dont le but était toujours de rendre ceux-ci plus explicites. Leur genèse, les débats qu'ils ont (ou non) suscités sont autant d'indices sur la place occupée par les bibliothèques dans la société de leur temps. Le dossier se clôt sur un chapitre encore ouvert, celui de la restructuration de la Bibliothèque nationale et universitaire de Strasbourg, qui nous confronte aux préoccupations et aux problématiques de la lecture publique et universitaire d'aujourd'hui - en un mot, à son identité.

\section{Christophe Didier}

